\title{
¿QUÉ DEMONIOS QUIERES? SOBRE LA MODIFICACIÓN NOMINAL ENFÁTICA EN ESPAÑOL
}

\author{
¿QUÉ DEMONIOS QUIERES? ON THE ENPHATIC NOMINAL \\ MODIFICATION IN SPANISH LANGUAGE
}

\author{
Enrique Pato \\ Université de Montréal \\ enrique.pato-maldonado@umontreal.ca
}

\begin{abstract}
RESUMEN
Los interrogativos (o palabras-Q) quién, dónde, cómo, cuándo, por qué, qué y cuál pueden verse modificados por nombres como demonios y carajo(s) y actuar en ese contexto como determinantes. Se ha señalado la importancia de este tipo de sustantivos (wh-the-hell, en inglés) para la teoría del movimiento, denominándolos 'agresivamente no vinculados al discurso'. Desde distintos marcos teóricos se han estudiado estas estructuras, sobre todo en inglés, chino y japonés. Para el español los estudios específicos (gramaticales o léxicos) sobre estas construcciones siguen siendo muy escasos, de ahí la pertinencia de un trabajo que permita conocer mejor el fenómeno y dar cuenta de los casos donde los interrogativos aparecen como modificadores nominales delante de un nombre de naturaleza enfática en (la historia del) español. En este trabajo me detendré en dar a conocer un caso concreto de fraseología (Qué demonios $\sim$ narices $\sim$ carajos $\sim$ puñetas quieres) para mostrar el tipo de nombres enfáticos que pueden aparecer delante de una palabra-Q en español, qué interrogativos son los más utilizados y qué significado léxico adquiere este tipo de construcción en conjunto, como unidad de sintaxis total o parcialmente fija que es.
\end{abstract}

\begin{abstract}
Spanish Interrogatives (or Q-words) quién, dónde, cómo, cuándo, por qué, qué y cuál can be modified by names like demonios and carajos and act in that context as determiners. The importance of this type of nouns (wh-the-bell, in English) has been pointed out for the theory of movement, calling them 'Aggressively not linked to Discourse'. These structures have been studied from different theoretical frameworks, especially in English, Chinese and Japanese. For Spanish, specific studies (grammatical or lexical) on these constructions are still very scarce, hence the relevance of a work that allows us to better understand the phenomenon and account for the cases where interrogatives appear as nominal modifiers in front of a name of emphatic nature in (the history of) Spanish. In this work I will present a specific case of phraseology (Qué demonios $\sim$ narices $\sim$ carajos $\sim$ puñetas quieres) to show the type of emphatic nouns that can appear before a Q-word in Spanish, which interrogatives are the most used and what lexical meaning this type of construction acquires as a whole, as a totally or partially fixed unit of syntax.
\end{abstract}

Keywords: Spanish, grammar, phraseology, interrogatives, emphatic nouns. 


\section{INT'RODUCCIÓN}

En español actual, al igual que sucede en otras lenguas, los interrogativos (expresionesQu o palabras-Q) quién, dónde, cómo, cuándo, por qué, qué y cuál pueden verse modificados por nombres como demonios, entre muchos otros, y actuar en esos contextos sintácticos precisos como determinantes (¿Qué demonios quieres?). Pesetsky (1987) ya señaló la importancia de este tipo de sustantivos (the bell 'demonio' y similares, en inglés) para la teoría del movimiento, denominándolos 'agresivamente no vinculados al D[iscurso]'. Sin embargo, Oguro (2017) ha mostrado que sí pueden estar vinculadas a D, pues la respuesta a estas preguntas puede estar en un conjunto proporcionado por el contexto. Por ello, la naturaleza de estas frases no sería tanto la vinculación o no a $\mathrm{D}$, sino su enfoque identificativo, que -como veremos más adelante- tiene que ver con varias propiedades interpretativas.

Desde distintos marcos teóricos, varios autores se han acercado al estudio de estas estructuras sintácticas, sobre todo para el caso del inglés, el chino y el japonés (véase, por ejemplo, den Dikken y Giannakidou, 2002; Huang y Ochi, 2004; Bayer y Cheng, 2015; Oguro 2017, entre otros). En el caso concreto del español, los estudios específicos -tanto gramaticales como léxicos- sobre estas construcciones son casi inexistentes, de ahí la pertinencia de un trabajo como el presente para conocer un poco mejor este fenómeno y dar cuenta de ejemplos como los siguientes (cf. 1), tomados de la prensa escrita, donde los interrogativos aparecen como modificadores nominales delante de un nombre de naturaleza enfática (demonios).

(1) a. ¿Quién demonios es Juvenal Acosta? (El Economista, 09/08/2017, México).

b. ¿Dónde demonios se ha metido Hilary Swank? (Fotogramas, 04/07/2016, España).

c. ¿Cómo demonios vamos a entender el mundo? (El Día, 16/04/2017, España).

d. ¿Cuándo demonios piensan arreglar el servicio de internet? (Claro, 12/07/2013, Guatemala).

e. ¿Por qué demonios quieren ser periodistas? (El País, 18/03/2016, España).

f. ¿Qué demonios es el populismo? (El Financiero, 28/02/2017, México).

g. ¿iCuál demonios es la cuarta boca!? (3DJuegos.com, Kin-iroX, 09/07/2015).

Desde el punto de vista léxico, esta modificación (¿Qué demonios quieres?) puede ser entendida como un ejemplo concreto de fraseología, en el sentido de 'unidad de 
sintaxis fija" ${ }^{1}$, propia del habla coloquial, aunque no solo de este registro de habla, como veremos en algunos de los ejemplos que ofrecemos en este trabajo.

Entre los usos que presentan, estas unidades pueden servir para mostrar asombro (cf. 1a-b), enfado (cf. 1c), molestia (cf. 1d), negación o rechazo (cf. 1f), y adquieren un marcado matiz enfático. Por lo general, estas oraciones se interpretan como preguntas retóricas (cf. 1e), o incluso como exclamaciones (cf. 1g), y así lo indica la RAE/ASALE (2009, pp. 1567, 1772 y 3190) cuando señala que este tipo de interrogaciones se convierten en "pregunta retórica o exclamación".

En cuanto a su distribución geográfica se refiere, se ha indicado que no son empleadas por igual en el mundo hispanohablante (RAE/ASALE, 2009, p. 1567), pero no se ha precisado todavía su extensión.

Teniendo en cuenta todo lo anterior, el objetivo general de este trabajo es ofrecer una primera caracterización de estas estructuras en español. Para ello, me detendré en primer lugar, en conocer el tipo de nombres enfáticos que pueden aparecer delante de una palabra-Q en español. En segundo lugar, conocer qué interrogativos son utilizados, y si alguno de ellos presenta un empleo mayor que los demás. En tercer lugar, interesa saber si existe documentación histórica del fenómeno. Después, y gracias a nuevos datos obtenidos en un corpus lingüístico, que caracterizo más adelante, es mi intención mostrar dónde se emplean estas construcciones en la actualidad, esto es, su distribución geográfica, tomando como ejemplo base para ello cuatro de los nombres enfáticos registrados. Además, resulta necesario entender el valor que adquieren estas construcciones en conjunto, su significado léxico como unidades de sintaxis total o parcialmente fijas. Por último, unas conclusiones cierran el trabajo de estas construcciones con modificadores nominales enfáticos.

El corpus lingüístico que empleo en esta ocasión es el Corpus del español: Web/Dialectos. Como es sabido, se trata de un corpus muy amplio (cuenta con más 2100 millones de palabras procedentes de más de 2 millones de páginas web fechadas

\footnotetext{
${ }^{1}$ En el sentido de combinación estable de dos (o más elementos) que puede funcionar como elemento oracional y cuyo significado no es la suma de los sentidos de sus componentes (Casares, 1969, p. 170). Para López Bobo (2002), por ejemplo, en ¿Qué demonios pasa aquí? hay una interjección (demonios) integrada en una oración (¿Qué pasa aquí?). Cf., además, Rivas González (2005-2006, pp. 310-311).
} 
entre 2010 y 2018), que genera resultados ponderados, ya que cada uno de los países de habla hispana está proporcionalmente representado. Los datos obtenidos serán sometidos, además, a una prueba estadística básica.

\section{LOS NOMBRES ENFÁTICOS}

Como vimos en los ejemplos de (1), el nombre que aparece en estas estructuras (demonios) hace que la locución sea considerada como una construcción enfática (RAE/ASALE, 2009, p. 3190). Las marcas que llevan estos nombres enfáticos o intensivos en el Diccionario de la lengua española y en el Diccionario de americanismos, por ejemplo, son las de "coloquial", "vulgar", "malsonante" y "festiva". Por tanto, los sustantivos enfáticos suelen tener un carácter descortés o agresivo (Di Tullio, 2010, p. 76), aunque parece que no es así en todos los casos ni en todas las lenguas ${ }^{2}$. Algunos son coloquiales (cf. 2a fregados, y $2 \mathrm{~b}$ porras), otros vulgares y malsonantes (cf. 2c vergas, y $2 \mathrm{~d}$ cojones).

(2) a. Apenas da la hora de la comida, sales disparado a la fonda más cercana a echarte tu consomé de pollo, arroz (algunos infames lo piden con huevo), guisadito, postre y café para no dormirme. ¿Cómo fregados no nos va a dar sueño después de semejante comilona? (México).

b. No sé qué porras hice pero al intentar bajarme de la bici calculé mal la distancia al suelo, perdí el equilibrio de la manera más tonta y aterricé pesadamente sobre el cachete posterior izquierdo (Bolivia).

c. Para mi sorpresa con los ruegos de la gente de no armar relajo, el muy imbécil desistió de su idea original. ¿Qué vergas le pasa a la gente hoy en día?, pareciera que de repente todos tienen sentimientos, y todos ruegan por la paz de manera ficticia (Ecuador).

d. Salgo del colegio hace poco y recojo a mi hijo. Hay un kiosko con chucherías. Un chaval tira un papel al suelo. Cuando veo estas cosas, me duele, me machaca. Le digo: ¿A que en tu casa no lo haces? Recoge eso. Llega la abuela: ¿Quién cojones te has creído que eres? La sobreprotección de los padres y familiares malcría a nuestros hijos (España).

En lo que sigue, y sin ánimo de ser exhaustivo, presento una primera lista de nombres enfáticos (y un par de locuciones) que se documentan hoy día en español en el interior de estas estructuras. Como ha sido señalado, estas frases no son usadas "por igual en todos los países hispanohablantes, ni en los mismos niveles de lengua" (RAE/ASALE,

${ }^{2}$ El uso ofensivo de estos nombres depende del contexto y de la intención del hablante, así como de la actitud del oyente. Por otro lado, lenguas como el griego antiguo, por ejemplo, cuentan con nombres enfáticos [+humanos] de sentido peyorativo y de sentido afectivo (cf. Ballesta García, 2001, p. 49). 
2009, p. 1567), por ello, en aquellos nombres que son de empleo general en español actual no aparece ninguna localización geográfica, solamente “de uso general”. En los nombres que no son generales, en cambio, figuran los países donde se registra su uso, según los datos obtenidos en el Corpus del español: Web/Dialectos. Por otro lado, y dado que las connotaciones particulares de cada uno de estos nombres enfáticos deben describirse por separado, más adelante conoceremos el empleo (número de casos y porcentajes) y la distribución geográfica precisa de algunos de ellos; en concreto de los nombres carajos, demonios, narices y puñetas. La lista es la siguiente:

- $\quad \operatorname{carajo(s)~(también~carayo,~caray~y~caramba)~('lugar~muy~lejano';~'persona~mala';~eufemístico~}$ 'pene'), malsonante, denota fuerte negación, decisión y contrariedad. De uso general'3.

- $\quad c a r r i z o(s)$ ('planta, hierba'), coloquial, expresa disgusto, rechazo o sorpresa. Especialmente usado en Venezuela, pero también en México y Panamá.

- cbingadera(s) ('objeto o hecho molesto'; 'practicar el coito'), malsonante. En México, Guatemala, El Salvador y Bolivia.

- chingados ('que ha sufrido daño'; 'prostituta'), malsonante. En México y Guatemala, pero también en los demás países centroamericanos, los Andes y el Río de la Plata.

- cojones ('testículos'), malsonante, para expresar diversos estados de ánimo, especialmente extrañeza o enfado. Frecuente en España, pero también en México, Colombia, Cuba y República Dominicana.

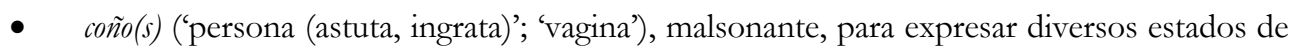
ánimo, especialmente extrañeza o enfado. Uso propio de España, pero también del Caribe, Venezuela y México.

- $\quad$ cuentos ('embuste, engaño'; 'chisme, enredo'; 'millón'), coloquial. En España, Colombia y Perú, entre otros países. El Diccionario de americanismos incluye la locución iqué cuento! solo para Costa Rica y República Dominicana.

- cuernos ('infidelidad'), festiva, para expresar sorpresa o asombro. En el Río de la Plata (especialmente en Argentina), Perú, Venezuela y España. Poner los cuernos aparece en Covarrubias (1611)

- $\quad c o r n o(s)$ ('cuerno'), popular, expresa negación y rechazo. Especialmente en Argentina y Uruguay.

\footnotetext{
${ }^{3}$ En el Diccionario Nacional ó gran diccionario clásico de la lengua española de Domínguez (1846-1847), por ejemplo, figura solo la voz caraja: "Interjección vulgar impropia de la cultura y buena educación. Es imitacion de otra más indecente, terminada en o en lugar de a que se omite por decencia" (cf. Quilis Merín, 2007, p. 284).

${ }^{4}$ En la entrada de Cuerno, el diccionario de Domínguez (1846-1847) indica lo siguiente: “[...] Hay otras frases menos decentes, ó menos oportunas, que no consideramos de caso mencionar. Tambien se usa la palabra cuerno como especie de interjeccion ó esclamacion equivalente, en sentido de sorpresa, de disgusto, de ira ó rabia etc. lo cual no requiere ejemplos ciertamente, aunque no lo trae la Academia" (cf. Quilis Merín, 2007, p. 284).
} 
- demonios ('diablo'), coloquial. Otras formas son demonche(s) ('demonio'), coloquial; demontre(s), coloquial; diache, dianches, coloquial; diantre(s) (eufemístico), coloquial; diaño, diañe, coloquial. De uso general.

- diablos ('persona astuta'; 'calumniador'), coloquial, para expresar sorpresa, extrañeza, admiración o disgusto; pero también para expresar impaciencia o admiración. De uso general ${ }^{5}$. Otros nombres, incluidos en el Diccionario de la lengua española, para denominar al diablo son candanga(s), candinga, candongo, mandinga, pingo, uñudo, ñuzco, cachudo y gualicho, de empleo en México, El Salvador, Honduras, Nicaragua, Venezuela y Chile, entre otros países.

- flautas ('instrumento musical'; eufemístico 'pene’), coloquial. En México y España, sobre todo.

- fregados ('acción y efecto de fregar'; 'persona corriente'; 'enredo, embrollo'), coloquial, expresa enojo, extrañeza o duda. En México, Guatemala, Honduras, El Salvador, Colombia y Venezuela. El Diccionario de americanismos incluye iqué fregados! solo para México.

- gaitas ('instrumento musical'; 'cosa molesta'; eufemístico 'pene'), coloquial. En España, México y Colombia.

- historias ('mentira, pretexto'; 'cuento, chisme, enredo'), coloquial. En España, Cuba, México, Colombia, Argentina y Uruguay.

- $\quad$ hostia(s) (también hostia puta) ('lo que se ofrece en sacrificio'; 'golpe'), malsonante, denota sorpresa, asombro, admiración. Especialmente en España, Puerto Rico y Argentina.

- huevos (eufemístico 'testículos’), vulgar. En España, México, Guatemala, El Salvador, Costa Rica, Perú y Argentina.

- leche(s) ('semen'; 'golpe'; 'suerte'), vulgar, indica sorpresa, asombro y admiración. En España, México, El Salvador, Honduras, Cuba, Puerto Rico, Costa Rica, Colombia y Argentina. El Diccionario de americanismos incluye la locución iqué leche! en El Salvador, Honduras, Nicaragua, Panamá, Puerto Rico, Ecuador y Bolivia, empleada para expresar admiración por la suerte de alguien.

- mandangas ('tonterías, cuentos, pejigueras', 'droga'). Se registra especialmente en España.

- $\quad$ mierda(s) ('excremento’), malsonante, expresa contrariedad o indignación. De uso general.

- $\quad$ minga(s) (de Dominga; eufemístico 'pene'), malsonante, expresa negación y rechazo. Numerosas son las voces que se pueden emplear para hacer mención del pene: mondonga, badajo, guasca, tolete, pincho, pico, pito, palo, pájaro, paloma, cola, entre muchos otros; nombres que -según el Diccionario de la lengua española- se registran en Guatemala, Nicaragua, Panamá, Uruguay, Cuba, República Dominicana, Perú, Costa Rica y Chile, entre otros países.

- narices ('órgano del rostro humano'), coloquial, denota enfado o molestia. De uso general.

- patrañas ('mentiras, burlas'; 'cuentos'), coloquial. De uso general.

- $\quad$ pejzgueras ('cosa que sin traernos gran provecho nos pone en problemas y dificultades'), coloquial. En España.

${ }^{5}$ Echegaray (1887, p. 798) indica que ¿Qué diablos! y ¿Cómo diablos! son “modos de hablar que se juntan frecuentemente à las expresiones de impaciencia ó de admiración”. Este es el único empleo de nombre “enfático" que figura en su diccionario. Esta definición está copiada de Domínguez (1846-1847): "Diablo! Especie de interjección significativa de sorpresa, de admiración de asombro, de incredulidad irónica y maligna, etc. segun el caso. = ¿Qué diablos? ¿Cómo diablos? Modos de hablar que se juntan ó se siguen frecuentemente á las espresiones y demostraciones de admiración, de impaciencia, de ira, de disgusto, de incredulidad, ó duda etc.” (cf. Quilis Merín, 2007, p. 285). 
- $\quad$ pelotas (eufemístico 'testículos'), vulgar. En Argentina y España, sobre todo.

- $\quad$ pichas (eufemístico 'pene’), malsonante. En España.

- $\quad$ pijas (eufemístico 'pene'), malsonante. En España y Argentina.

- $\quad$ pinche(s) ('de mala calidad'; 'ruin, despreciable'; metafórico 'el valentón de navaja [que pincha]'), malsonante. Especialmente en México, pero también en Guatemala y El Salvador.

- $\quad$ pinga(s) ('percha’; 'eufemístico 'pene’), coloquial. En Colombia, Costa Rica, Cuba, Ecuador, Guatemala, Honduras, Nicaragua, Panamá, Perú, República Dominicana y Venezuela.

- pollas ('gallina nueva'; eufemístico 'pene’), malsonante. Especialmente en España.

- $\quad$ porras ('palo, maza'; 'vanidad, presunción'; eufemístico 'pene’), coloquial, sirve para expresar disgusto o enfado. En España, México, Colombia y Bolivia.

- puñetas ('dificultad, molestia'; eufemístico 'masturbación'), coloquial y malsonante, respectivamente, sirve para expresar asombro o enfado. Especialmente en España y México.

- $\quad$ putas ('prostituta'), malsonante, para ponderar o enfatizar la ausencia o la escasez de algo. De uso general. El Diccionario de americanismos incluye la locución iqué putas! en Guatemala, El Salvador, Honduras y Bolivia, empleada para expresar asombro, sorpresa o rechazo.

- polillas ('mariposa nocturna'; eufemístico 'prostituta'), coloquial. En México, Guatemala, El Salvador, Nicaragua, Costa Rica, Ecuador, Colombia, Bolivia, República Dominicana y España.

- rábanos ('planta, hortaliza'), coloquial, para rehusar algo o expresar que algo no importa. En España y México.

- $\quad$ rayos ('línea de luz'; 'chispa eléctrica'), coloquial, para manifestar ira o enojo. De uso general. El Diccionario de americanismos incluye la locución iqué rayo! solo para Panamá, para expresar que no se concede importancia a un asunto.

- $\quad$ verga(s) ('palo'; 'golpe físico o moral'; 'asunto'; eufemístico 'pene'), vulgar, para expresar sorpresa, protesta, disgusto o rechazo. En México, Guatemala, Ecuador y España, entre otros países.

- $\quad$ niño muerto, expresión coloquial, sirve para mostrar rechazo o desprecio, generalmente de forma exclamativa (interjección). Procedería de la locución niño envuelto ('niño muerto antes de ser bautizado'). Puede aparecer precedido de otro nombre (Qué $N$ ni qué niño muerto) ${ }^{6}$. De uso casi general.

- ocho cuartos, expresión coloquial, sirve para subrayar desacuerdo con algo o incredulidad, generalmente de forma exclamativa (interjección). Procede de cuartos ('fracción de la antigua moneda española'). Puede aparecer precedido de otro nombre (Qué $N$ ni qué ocho cuartos) ${ }^{7}$. En Argentina, Cuba, España, México y Perú, entre otros países.

${ }^{6}$ Es decir, puede aparecer como fórmula exclamativa con la conjunción $n i$, tanto sin diferenciación en la forma (qué A ni qué $A$ ) como con diferenciación (qué A ni qué B) (RAE/ASALE, 2009, p. 3198), como por ejemplo en: «Pero qué Ley de Transparencia ni qué niño muerto van a hacer estos dos grandes felones PP y PSOE si lo que tienen ambos no es un partido, es un pozo negro» (España).

7 Sucede lo mismo que en el caso anterior: «Esos juegos tan lindos nos llenaban la vida de alegría, de buenos momentos quemando calorías sin sentirlo. Qué Nintendo ni que ocho cuartos, mucho menos eso de estar texteando, ¡ah chispas!, ahora los patojos ya ni ejercicio hacen» (Guatemala). 
Como podemos observar en la lista precedente, muchos de los nombres presentan una relación semántica de sinonimia y están vinculados a connotaciones de carácter sexual. Por otro lado, la gran mayoría de las acepciones específicas que poseen estos nombres enfáticos, cuando aparecen especialmente en plural ${ }^{8}$, "no se deducen de forma sistemática del significado de los singulares correspondientes" (RAE/ASALE, 2009, p. 176), por lo que estos significados deben estar dentro de los rasgos semánticos de cada nombre (phi features). Muchos de ellos todavía no figuran en los diccionarios académicos, ya que las voces malsonantes o groseras tradicionalmente se eluden en la lexicografía (cf., por ejemplo, Quilis Merín, 2007, p. 284). Es lógico pensar que, con el paso del tiempo, y su uso reiterado en cada una de las comunidades de habla, estos nombres adquieren dichos significados enfáticos. Volveré sobre este punto al final de este apartado.

Una pregunta básica que nos podemos plantear es qué tienen en común todas estas palabras de la lista. Los nombres enfáticos, denominados aggressively non D-linked (agresivamente no vinculados al discurso), modifican a pronombres y adverbios interrogativos no vinculados al contexto (Pesetsky, 1987) ${ }^{9}$, es decir, ninguna persona, lugar o cosa satisface las condiciones de la pregunta como parte del discurso previo (¿Quién demonios dijo eso?; ¿Dónde carajos estuviste ayer?; ¿Qué mierdas estás haciendo?), o lo que es lo mismo, la respuesta apropiada no figura en el discurso previo. Como ha sido indicado, estos nombres enfáticos o intensivos licencian una inferencia negativa ('se supone que nadie X'). Para Lee (1994), por ejemplo, se trata de una inferencia de

\footnotetext{
${ }^{8}$ Queda pendiente conocer por qué estos nombres enfáticos aparecen generalmente en su forma plural. La idea de que la $-s$ pueda ser reanalizada como marca discursiva de intensidad expresiva ha sido propuesta por Company Company (2017), en casos como jaguas!, jcuernos!, ;sopas!, para el español de México. En concreto, esta autora defiende un cambio de nombre (agua) a expresión interjectiva (jagua.) y de cuantificador plural (aguas) a cuantificador intensivo (jaguas.). En el caso que nos ocupa (iQué demonios haces aquí?) la -s podría ser considerada como una más de las estrategias gramaticales de afectación o actitud con las que cuenta el español. De hecho, creo que estos sustantivos sufren un proceso de gramaticalización (de pseudoadverbialización) y adquieren esa marca adverbial (-s). En otras lenguas romances, como el francés o el italiano, se prefieren las formas en singular (Où diable est-il allée?; Che diavolo ci fai qui ? . La relación entre el español y otras lenguas será abordada de un futuro trabajo.

${ }^{9}$ No obstante, como vimos en la introducción, las frases-Q pueden estar vinculadas al discurso. Esto sucede especialmente cuando el hablante y el oyente tienen en mente un conjunto de elementos individuales o de personas como candidatos para la respuesta: ¿Quién demonios tiene la tarjeta? (en un juego de cartas); ¿Quién diablos es el corredor más rápido en nuestro equipo? (cf. Huang y Ochi, 2004; Oguro, 2017).
} 
[sorpresa], esto es, una inferencia pragmática que transmite la actitud negativa del hablante hacia el contenido de la pregunta, y que, además, puede coexistir con la posibilidad de una respuesta positiva (¿Quién demonios dijo eso? - Lo dijo Luis). En suma, los nombres como demonios están motivados por una presuposición que expresa una actitud negativa por parte del hablante (Bayer y Cheng, 2015).

Por otro lado, siguiendo a estos autores, también se ha señalado que no pueden ocurrir in situ ( ${ }_{i} \dot{H}$ a dicho qué demonios?) y que no son compatibles con lecturas no únicas cuando ocurren en la raíz de preguntas múltiples (?/*iQuién dijo qué demonios?). De hecho, den Dikken y Giannakidou (2002), al estudiar su distribución en preguntas individuales, los asemejan con los términos de polaridad ${ }^{10}$. Además, como bien indica Di Tullio (2010, pp. 76 y 80), las preguntas segmentadas finales rechazan estos sustantivos en español (*iQué diablos lo dejaste, bajo la cama?), así como las preguntas segmentadas iniciales (*iQué diablos, lo dejaste bajo la cama?).

$\mathrm{Al}$ igual que sucede en otras lenguas como el chino (en concreto con el adverbio daodi 'hasta el fondo', cf. Huang y Ochi, 2004), en español demonios puede considerarse como un sustantivo adverbial, que aparece en una posición preverbal adjunta, mientras que el interrogativo asociado puede aparecer en posición argumental (quién, qué: ¿Qué demonios quieres?) o no argumental (por qué, cómo: ¡No sé cómo demonios ha llegado hasta aquí.).

Como señalábamos anteriormente, pero no desarrollaremos en profundidad en este trabajo, los nombres enfáticos adquieren con el uso y el paso del tiempo estos significados nuevos (rábano(s) 'planta, hortaliza'> rábanos [actitud], como nuevo componente léxico). Es decir, se van fijando semánticamente, se sitúan más a la izquierda, se vacían de su significado originario y adquieren un nuevo valor pragmático. Esta inferencia pragmática (o presuposición) es negativa y transmite la actitud del hablante hacia el contenido de la pregunta: ¿Qué demonios has hecho? implica

\footnotetext{
${ }^{10}$ Serían términos de polaridad por varios motivos: i) la posibilidad de respuestas negativas con verbos modales (¿Quién carajo podría comprar compraría ese libro?); ii) su aparición como complemento de verbos asertivos como saber ((No) sé quién demonios compraría ese libro); iii) la disponibilidad de lecturas de pares en múltiples estructuras (¿Quién demonios está enamorado de quién?); y iv) su interacción con otros cuantificadores (¿Qué demonios compraban todos para Luis?) (cf. den Dikken y Giannakidou, 2002).
} 
generalmente que 'has hecho algo malo'. Lo que tienen en común, por tanto, es que la respuesta apropiada no suele figurar en el discurso previo ('no sé lo que has hecho').

\section{LOS IN'T'ERROGA'TIVOS (O PALABRAS-Q)}

En principio, no hay restricciones en cuanto a la palabra-Q (interrogativa) que puede formar parte de este tipo de construcciones (cf. los ejemplos de 1). Sin embargo, como veremos en detalle más adelante (cf. las tablas 1-4), cuál es la forma menos frecuente, ya que "la incógnita que introduce se suele determinar en un contexto previamente mencionado" (RAE/ASALE, 2009, p. 1567), y acabamos de ver que la respuesta a estas estructuras no suele figurar en el discurso previo. En efecto, como es sabido, cuál sirve para pedir que se precise una referencia previa (RAE/ASALE, 2009, p. 1643) y, al igual que which en inglés, se comporta como intensificador totalizador, no individualizador, de ahí que no sea compatible con estos sustantivos enfáticos (*Which the bell book does he want to read?). En efecto, tanto which como cuál asumen la existencia de conjunto(s), es decir, son presuposicionales, y están relacionados con el discurso anterior (cf. Huang y Ochi, 2004, para el caso del inglés). No obstante, como podemos observar en los ejemplos de (3), en español es posible registrar casos con el pronombre cuál. Por ello, parece que su empleo dependería más de la semántica que de la estructura del discurso (Fiengo, 2007, p. 99).

(3) a. Will Smith estaba en la alfombra roja de la premiere de Hombres de Negro 3 en Moscú, cuando un reportero ucraniano trató de besarlo insistentemente, a lo que el actor reaccionó con un empujón y un golpe en la cara, y preguntándole: ¿cuál demonios es tu problema? (México).

b. El capitalismo está en crisis en todo el mundo, pero, ¿cuál diablos es la alternativa? Pues, ¿qué pasa con las reflexiones de un cierto filósofo alemán del siglo XIX? Sí, Karl Marx se va al mainstream, y Dios sabe dónde va a terminar (El Salvador).

c. Cuando terminé con el celular, me bajé y fui a tocar el timbre, ipero había seis! ¿Y cuál carajo iba a tocar? ¿¿Por qué pensó en tocar el timbre? -Porque quería que fuera Marisol la que me dijera que me vaya, y que me pagara los dieciséis pesos del viaje (Argentina).

d. No sé, salí con esa sensación que a menudo me asalta de que he visto una película que tiene un mensaje, pero no sé cual cojones es el mensaje. Me pasó con el viaje de Chihiro. Cojonuda sí, pero no sé cual es el mensaje (España).

Por otro lado, el cuantificador cuánto no forma parte de estas construcciones, ya que solo los interrogativos como formas de interpretación referencial, esto es, cuando designan individuos o cosas particulares (quién diablos; cómo narices; qué cojones), pueden 
aparecer. En efecto, los casos registrados en que figura la forma cuánto, aunque posibles (con nombres en singular como carajo [cf. 4]), son escasísimos en el corpus consultado.

(4) En ese tipo de tortura siempre había alguien que hubiera hecho el juramento hipócrita, aunque por más que fueran doctores en medicina nadie puede saber cuánto carajo bancás vos adentro... Y entiendo que en muchos casos, cuando la quedaron o cuando murieron, fue porque hubo una mala praxis (Uruguay).

Otro dato de interés es que las palabras-Q admiten la coordinación mediante la conjunción $y$ (cf. $5 \mathrm{a}-\mathrm{b})^{11}$. Con respecto a su posición, el interrogativo y el nombre enfático deben ocurrir localmente dentro de la misma cláusula (cf. 5c), y no a distancia el uno del otro (cf. 5d) (den Dikken y Giannakidou, 2002) ${ }^{12}$.

(5) a. fui de las babillúas que compró la taquilla para el Concierto de Calle 13, sin saber donde y cuando carajo era el concierto (Puerto Rico).

b. Todavía no tengo en mis manos un postout Addon como para saber como y que carajos hace ya que por lo único que se ve en la imagen se podría utilizar otro método que no sea esta chotada para hacerlo (Argentina).

c. Qué demonios crees que debo hacer.

d. *Qué crees demonios que debo hacer.

\section{NUEVOS DATOS}

Como quedó indicado en el apartado de la introducción, los datos que presento en este trabajo proceden de la revisión del Corpus del español: Web/Dialectos. Las búsquedas se realizaron entre los meses de septiembre y octubre de 2018 e incluyeron los sustantivos carajo, demonio y puñeta en singular, así como sus respectivos plurales (carajos, demonios, puñetas) y el nombre narices, y las palabras-Q con y sin acentuación (que/qué), en cada uno de los países hispanohablantes, con la excepción de los Estados Unidos.

Aunque uno de los objetivos de este trabajo es conocer mejor las connotaciones particulares de los nombres enfáticos, así como su distribución geográfica precisa, resulta imposible mostrarlos todos. La inclusión de solo cuatro nombres se ha visto motivada, pues, por cuestiones de espacio. Sin embargo, creo que esta selección ofrece

\footnotetext{
11 A este respecto, la RAE/ASALE (2009, p. 1661) indica que la coordinación no sucede cuando por qué aparece en segunda posición. En estos casos habría dos lecturas posibles: la lectura causal y la lectura de sugerencia.

12 En otras lenguas como el francés también se bloquea la opción in situ (Où diable est-il allé?, pero *Il est allé où diable?) (Obenauer, 1994).
} 
un panorama general en cuanto a su documentación y frecuencia de aparición (análisis cuantitativo) en el mundo hispanohablante.

Los casos repetidos, frecuentes en los textos de internet, fueron suprimidos del cómputo general. Los datos obtenidos, por nombre enfático e interrogativos, con sus respectivos totales y el porcentaje global, son los siguientes.

4.1. CARAJOS

\begin{tabular}{|c|c|c|c|c|c|c|c|c|}
\hline CARAJOS & qué & dónde & cómo & cuándo & quién & por qué & cuál & TOTAL \\
\hline Argentina & 712 & 45 & 134 & 13 & 204 & 29 & 1 & 1138 \\
\hline Bolivia & 37 & 1 & 6 & 2 & 13 & - & - & 59 \\
\hline Chile & 33 & 2 & 8 & - & 6 & 5 & - & 54 \\
\hline Colombia & 511 & 90 & 67 & 8 & 59 & 22 & - & 757 \\
\hline Costa Rica & 44 & 13 & 13 & - & 12 & - & - & 82 \\
\hline Cuba & 68 & 5 & 7 & 3 & 19 & - & - & 102 \\
\hline Ecuador & 112 & 15 & 19 & 3 & 14 & 8 & - & 171 \\
\hline El Salvador & 36 & 4 & 5 & - & 13 & - & - & 58 \\
\hline España & 457 & 27 & 64 & 6 & 95 & 32 & 1 & 682 \\
\hline Guatemala & 40 & 5 & 15 & - & 3 & 8 & - & 71 \\
\hline Honduras & 19 & - & 3 & - & 3 & 4 & - & 29 \\
\hline México & 362 & 45 & 62 & 2 & 63 & 20 & - & 554 \\
\hline Nicaragua & 8 & 2 & 2 & - & 1 & 3 & - & 16 \\
\hline Panamá & 50 & 3 & 14 & 2 & 7 & 1 & - & 77 \\
\hline Paraguay & 41 & 5 & 10 & - & 4 & 3 & - & 63 \\
\hline Perú & 223 & 17 & 47 & 6 & 31 & 13 & - & 337 \\
\hline Puerto Rico & 187 & 19 & 26 & 3 & 49 & 7 & - & 291 \\
\hline Rep. Dom. & 40 & 5 & 6 & 1 & 16 & 5 & - & 73 \\
\hline Uruguay & 99 & 10 & 13 & 2 & 25 & 4 & - & 153 \\
\hline Venezuela & 254 & 15 & 36 & 4 & 44 & 14 & - & 367 \\
\hline TOTALES & $\begin{array}{c}3333 \\
(64.92 \%)\end{array}$ & $\begin{array}{c}328 \\
(6.39 \%)\end{array}$ & $\begin{array}{c}557 \\
(10.85 \%)\end{array}$ & $\begin{array}{c}55 \\
(1.07 \%)\end{array}$ & $\begin{array}{c}681 \\
(13.26 \%)\end{array}$ & $\begin{array}{c}178 \\
(3.47 \%)\end{array}$ & $\begin{array}{c}2 \\
(0.03 \%)\end{array}$ & $\begin{array}{c}\mathbf{5 1 3 4} \\
(100 \%)\end{array}$ \\
\hline
\end{tabular}

TABLA 1. Distribución del sustantivo carajos, por países e interrogativos, según el Corpus del español 
La tabla precedente muestra que Argentina (1138 casos, $22.16 \%$ ), Colombia (757, $14.74 \%)$, España (682, $13.28 \%$ ), México (554, $10.79 \%)$, Venezuela (367, $7.14 \%$ ), Perú (337, 6.56 \%), Puerto Rico (291, 5.66 \%), Ecuador (171, 3.33 \%) y Uruguay (153, $2.98 \%$ ) son los países con un empleo mayor del nombre enfático carajo(s), sobre un total de 5134 casos registrados.

En cuanto al uso de los interrogativos, la jerarquía es: qué (64.92\%) quién cómo $\sim$ dónde $\sim$ por qué $\sim$ cuándo cuál $(0.03$ \%). La prueba ANOVA (análisis de varianza) de un factor realizada sobre los totales muestra que los datos de la tabla son altamente significativos $(F=14,1482, p=0,0005$, y valor crítico de $F=4,0981)$; esto es, las variables 'país' y 'palabra-Q + carajo(s)' están relacionadas.

En (6) figuran algunos ejemplos, procedentes de Argentina (cf. Ga qué carajos), Puerto Rico (cf. 6b quién carajo), México (cf. 6c cómo carajos) y Colombia (cf. 6d dónde carajos):

(6) a. ¿Leíste el tramo en que digo que no queremos ver más sangre ni soportamos que corran riesgo nuestros hijos? ¿Qué carajo leíste? Y si lo leíste, ¿por qué no lo tuviste en cuenta? (Argentina).

b. Además, ¿quién carajo te dijo que te ves bien de rubia? Tu trademark era el pelo rojo. De pelirroja te veías de maravilla (Puerto Rico).

c. Hace unas semanas soñé que estaba en el paradero de autobuses de CU (imagen aquí abajito) sin pantalones, (si, o sea sólo en calzoncillos), y yo: Vergas!, ¿cómo carajos llegué aquí? (México).

d. los fines de semana (que es cuando entro a chismosear y que son los días de mayor actividad de la red, supongo yo) la náusea se apodera de mí. ¿Dónde carajos ha quedado el pudor de la gente? (Colombia).

\subsection{DEMONIOS}

\begin{tabular}{ccccccccc}
\hline DEMONIOS & qué & dónde & cómo & cuándo & quién & por qué & cuál & TOTAL \\
\hline Argentina & 96 & 9 & 40 & - & 13 & 5 & - & 163 \\
\hline Bolivia & 17 & - & 6 & - & 2 & 3 & - & 28 \\
\hline Chile & 52 & 2 & 13 & 1 & 4 & - & - & 72 \\
\hline Colombia & 168 & 13 & 32 & - & 29 & 3 & - & 245 \\
\hline Costa Rica & 19 & 3 & 11 & - & 7 & 2 & - & 42 \\
\hline Cuba & 40 & 1 & 17 & - & 3 & - & - & 61 \\
\hline Ecuador & 43 & 4 & 15 & - & 5 & 2 & - & 69 \\
\hline El Salvador & 28 & 2 & 22 & - & - & 1 & - & 53 \\
\hline
\end{tabular}




\begin{tabular}{ccccccccc}
\hline España & 1160 & 72 & 278 & 13 & 130 & 26 & - & 1679 \\
\hline Guatemala & 73 & 3 & 11 & - & 10 & 1 & - & 98 \\
\hline Honduras & 20 & 6 & 9 & - & 4 & - & - & 39 \\
\hline México & 439 & 24 & 122 & 3 & 40 & 28 & 1 & 657 \\
\hline Nicaragua & 24 & 3 & 15 & 1 & 1 & 2 & 1 & 47 \\
\hline Panamá & 19 & - & 5 & - & - & 2 & - & 26 \\
\hline Paraguay & 11 & 1 & 5 & - & 2 & 1 & - & 20 \\
\hline Perú & 116 & 5 & 27 & - & 15 & 4 & - & 167 \\
\hline Puerto Rico & 32 & 4 & 12 & 1 & 6 & 1 & - & 56 \\
\hline Rep. Dom. & 15 & 1 & 7 & - & 1 & 3 & - & 27 \\
\hline Uruguay & 18 & 2 & 6 & - & 2 & - & - & 28 \\
\hline Venezuela & 97 & 6 & 20 & 1 & 14 & 3 & 1 & 142 \\
\hline TOTALES & $\begin{array}{c}2487 \\
(66.87 \%)\end{array}$ & $\begin{array}{c}(4.33 \%) \\
(1618.09 \%)\end{array}$ & $(0.54 \%)$ & $(7.74 \%)$ & $(2.34 \%)$ & $(0.08 \%)$ & $(100 \%)$ \\
\hline
\end{tabular}

TABLA 2. Distribución del sustantivo demonios, por países e interrogativos, según el Corpus del español

Según las cifras presentadas, España (1679 casos, $45.14 \%$ ), con casi la mitad de las ocurrencias, seguido por México (657, $17.66 \%$ ), Colombia (245, $6.58 \%$ ), Perú (167, $4.49 \%)$, Argentina (163, $4.38 \%$ ) y Venezuela (142, $3.81 \%)$ son los países con una tasa mayor de ejemplos del sustantivo demonios (3719 registros en total). La jerarquía en el uso del interrogativo sería la siguiente: qué $(66.87 \%) \sim$ cómo $\sim$ quién $\sim$ dónde $\sim$ por qué cuándo cuál $(0.08 \%)$.

La prueba ANOVA de un factor realizada sobre los totales muestra, de nuevo, que los datos de la tabla precedente son estadísticamente significativos $(\mathrm{F}=4,7580, p=$ 0,035, y valor crítico de $F=4,0981$, por lo que las variables 'país' y 'palabra-Q + demonios' están relacionadas.

En (7) figuran algunos ejemplos de España (cf. 7a qué demonios), Perú (cf. 7b cómo demonios), Colombia (cf. 7c quién demonios) y México (cf. 7d dónde demonios).

(7) a. ¿Realmente está ocurriendo esto? Miras las noticias. Resultados de partidos. Prensa rosa. Es como que no pasa nada malo. ¿Qué demonios está pasando? Un extraño se ríe de ti leyendo el periódico (España). 
b. adquirimos un viewsonic widescreen, con la base para colocar el ipod y toda la cosa pero para trabajar se ve aplastado, ¿porque? ¿cómo demonios se configura o se arregla? en el manual no dice nada (Perú).

c. Bono: ¿Quién demonios dijo que a las viejas nos gusta que nos den nalgadas? (Colombia). d. Hey tú... una simple y directa pregunta... qué es este lugar? Dónde demonios... se supone que me encuentro? Dijo seriamente clavando sus rojizos ojos en ella (México).

4.3. NARICES

\begin{tabular}{|c|c|c|c|c|c|c|c|c|}
\hline NARICES & qué & dónde & cómo & cuándo & quién & por qué & cuál & TOTAL \\
\hline Argentina & 4 & - & - & - & 1 & - & - & 5 \\
\hline Bolivia & - & - & - & - & - & 1 & - & 1 \\
\hline Chile & 3 & 1 & 1 & - & - & - & - & 5 \\
\hline Colombia & 22 & - & 3 & - & 3 & - & - & 28 \\
\hline Costa Rica & - & - & 1 & - & - & - & - & 1 \\
\hline Cuba & 5 & - & 1 & - & 2 & - & - & 8 \\
\hline Ecuador & 2 & 1 & 3 & - & - & - & - & 6 \\
\hline El Salvador & 15 & - & 1 & - & - & - & - & 16 \\
\hline España & 673 & 44 & 137 & 4 & 58 & 23 & - & 939 \\
\hline Guatemala & 3 & - & - & - & - & - & - & 3 \\
\hline Honduras & 1 & - & - & - & - & - & - & 1 \\
\hline México & 25 & 3 & 5 & - & 6 & 2 & - & 41 \\
\hline Nicaragua & 1 & - & - & - & 1 & - & - & 2 \\
\hline Panamá & 1 & - & - & - & - & - & - & 1 \\
\hline Paraguay & 1 & - & - & - & - & - & - & 1 \\
\hline Perú & 9 & - & 2 & - & - & 2 & - & 13 \\
\hline Puerto Rico & - & - & 1 & - & - & - & - & 1 \\
\hline Rep. Dom. & 1 & - & 1 & - & - & - & - & 2 \\
\hline Uruguay & 2 & - & 1 & - & - & - & - & 3 \\
\hline Venezuela & 1 & - & - & - & - & - & - & 1 \\
\hline TOTALES & $\begin{array}{c}769 \\
(71.33 \%)\end{array}$ & $\begin{array}{c}49 \\
(4.54 \%)\end{array}$ & $\begin{array}{c}157 \\
(14.56 \%)\end{array}$ & $\begin{array}{c}4 \\
(0.37 \%)\end{array}$ & $\begin{array}{c}71 \\
(6.59 \%)\end{array}$ & $\begin{array}{c}28 \\
(2.59 \%) \\
\end{array}$ & $\begin{array}{c}0 \\
(0 \%)\end{array}$ & $\begin{array}{c}1078 \\
(100 \%) \\
\end{array}$ \\
\hline
\end{tabular}

TABLA 3. Distribución del sustantivo narices, por países e interrogativos, según el Corpus del español 
Los datos obtenidos indican que, en comparación con los otros dos nombres enfáticos anteriores, el número de casos registrados de narices en este contexto es mucho menor (1078 en total). España es el país con un porcentaje de aparición más elevado (939 casos, $87.10 \%$ ), seguido por México (41, $3.80 \%$ ), Colombia (28, $2.59 \%$ ), El Salvador (16, $1.48 \%$ ), Perú (13, $1.20 \%)$, Cuba (8, $0.74 \%$ y Ecuador (6, 0.55 \%). En los demás países se documenta entre 1 y 5 casos. Por otro lado, no se registran ejemplos con el interrogativo cuál, por lo que la jerarquía a este respecto en el uso de la palabra-Q es como sigue: qué $(71.33 \%) \sim$ cómo $\sim$ quién $\sim$ dónde $\sim$ por qué $\sim$ cuándo $\sim$ cuál $(0 \%)$.

La prueba ANOVA de un factor realizada sobre los totales nos indica que, en esta ocasión, los datos no son estadísticamente significativos $(F=1,2863, p=0,263$, y valor crítico de $F=4,0981$ ), por lo que las variables 'país' y 'palabra-Q + narices' no estarían relacionadas. El hecho de que la $p$ no sea significativa (menor de 0,05 ) se puede deber a la baja frecuencia de casos de narices en trece de los países considerados, lo que hace que la prueba no sea concluyente, ya que los valores atípicos no siguen un patrón reconocible. En cualquier caso, es evidente que el nombre enfático narices tiene una distribución geográfica mucho menor que carajos y demonios.

Algunos de los ejemplos documentados en España (cf. 8a qué narices, y 8d dónde narices), Colombia (cf. 8b qué narices) y México (cf. 8c quién narices) son:

(8) a. ¿Qué narices os gusta de nosotras? Nos gustan las mujeres que no juegan. O mejor, nos gustan las mujeres que saben cuándo jugar (España).

b. ¿Qué narices hace este hombre? ¿Quién se cree para mandarme órdenes, y además tener el descaro de decirme abiertamente que me espía? (Colombia).

c. Pottermore debería aparecer entre los 10 juegos peores de la historia. Quién narices no se [h] a leído los libros ya para tener k leertelo de nuevo por internet... de $\mathrm{k}$ va el juego? (México).

d. ¿Se acuerdan del Climategate? ¿Dónde narices estaban las tablas de Excel para tirar de las orejas a esos genios y hacer bien los cálculos? (España).

\subsection{Puñetas}

\begin{tabular}{ccccccccc}
\hline PUNETAS & qué & dónde & cómo & cuándo & quién & por qué & cuál & TOTAL \\
\hline Argentina & - & - & - & - & - & - & - & 0 \\
\hline Bolivia & - & - & - & - & - & - & - & 0 \\
\hline Chile & - & - & - & - & - & 1 & - & 1 \\
\hline
\end{tabular}




\begin{tabular}{|c|c|c|c|c|c|c|c|c|}
\hline Colombia & 1 & - & 1 & - & 1 & 1 & - & 4 \\
\hline Costa Rica & - & - & - & - & - & - & - & 0 \\
\hline Cuba & 3 & - & - & - & 1 & - & - & 4 \\
\hline Ecuador & 1 & - & - & - & - & - & - & 1 \\
\hline El Salvador & - & - & - & - & - & - & - & 0 \\
\hline España & 114 & 11 & 24 & 3 & 16 & 13 & - & 181 \\
\hline Guatemala & - & - & 1 & - & 1 & - & - & 2 \\
\hline Honduras & - & - & - & - & - & - & - & 0 \\
\hline México & 6 & - & 2 & - & - & 1 & - & 9 \\
\hline Nicaragua & - & - & - & - & - & - & - & 0 \\
\hline Panamá & - & - & - & - & 1 & - & - & 1 \\
\hline Paraguay & - & - & - & - & - & - & - & 0 \\
\hline Perú & - & - & - & - & 1 & - & - & 1 \\
\hline Puerto Rico & 14 & 3 & 3 & 2 & 1 & 1 & - & 24 \\
\hline Rep. Dom. & 1 & - & - & - & - & - & - & 1 \\
\hline Uruguay & 1 & - & - & - & - & - & - & 1 \\
\hline Venezuela & 4 & - & - & - & - & - & - & 4 \\
\hline TOTALES & $\begin{array}{c}145 \\
(61.97 \%)\end{array}$ & $\begin{array}{c}14 \\
(5.98 \%)\end{array}$ & $\begin{array}{c}31 \\
(13.25 \%)\end{array}$ & $\begin{array}{c}5 \\
(2.13 \%)\end{array}$ & $\begin{array}{c}22 \\
(9.40 \%)\end{array}$ & $\begin{array}{c}17 \\
(7.26 \%)\end{array}$ & $\begin{array}{c}0 \\
(0 \%)\end{array}$ & $\begin{array}{c}234 \\
(100 \%)\end{array}$ \\
\hline
\end{tabular}

TABLA 4. Distribución del sustantivo puñetas, por países e interrogativos, según el Corpus del español

España (181 casos, $77.35 \%$ ), Puerto Rico (24, $10.25 \%$ ) y en menor proporción México $(9,3.84 \%)$ son los países donde se registran más casos del nombre enfático puñetas (234 casos en total). Con mucha menor frecuencia aparece también en Colombia, Cuba y Venezuela (4 casos, 1.70 \%), Guatemala (2, 0.85 \%), Chile, Ecuador, Panamá, Perú, República Dominicana y Uruguay (1 sola ocurrencia, $0.42 \%$ ). Al igual que sucedía con el nombre narices, no se registran ejemplos con el interrogativo cuál. La jerarquía, en este caso, es la siguiente: qué $(61.97 \%) \sim$ cómo $\sim$ quién $\sim$ por qué $\sim$ donde $\sim$ cuándo $\sim$ cuál $(0 \%)$.

En esta ocasión, la prueba ANOVA de un factor realizada sobre los totales tampoco es concluyente, ya que no arroja datos estadísticamente significativos $(\mathrm{F}=1,4153, p$ $=0,241$, y valor crítico de $\mathrm{F}=4,0981)$. No existe, por tanto, correlación entre el 'país' 
y la 'palabra-Q + puñetas'. Como vemos, en siete de los países considerados no se registran ejemplos y en otros diez el número de casos es muy bajo (entre 1 y 4 ocurrencias), estos valores atípicos impiden que el análisis de varianza sea eficaz.

En (9) figuran algunos de los ejemplos de Puerto Rico (cf. 9a qué puñetas) y España (cf. 9b-d cómo/ quién/ dónde puñetas).

(9) a. El PPD por su parte lo vio como una victoria y muestra de la incompetencia del equipo de gobierno de Fortuño. A todo esto, la reacción más frecuente entre el público general fue: ¿Qué puñetas es un dominio? (Puerto Rico).

b. todos los que la defienden admiten que lo que dicen son chorradas. Bien, pues si son chorradas, ¿cómo puñetas llegó nadie a la conclusión de que un holograma esperpéntico mejoraba el equilibrio? (España).

c. un familiar mío también tuvo una experiencia muy desagradable por el viejo tema de los niños sin DNI (equién puñetas se molesta en sacarle un DNI a un bebé de mes y medio?) (España).

d. Hay un libro muy interesante y con un título muy sugerente: ¿Alguien me puede decir dónde puñetas están mis maletas? A propósito de los derechos de los pasajeros aéreos (España).

Si bien estas cifras solo constituyen una primera aproximación cuantitativa al estudio de los nombres enfáticos en español actual, y únicamente he considerado cuatro nombres, varios son los datos de interés que podemos recuperar de las tablas presentadas. En primer lugar, los modelos revisados muestran que mientras que unos nombres enfáticos son de uso general al mundo hispanohablante (carajos y demonios), otros presentan una distribución geográfica mucho más limitada (narices y puñetas). Esta misma consideración podría ser válida para el resto de los nombres de nuestra lista. En segundo lugar, la jerarquía en el empleo de los interrogativos muestra una clara preferencia por la forma qué, y un rechazo por la forma cuál, tal y como se había considerado en un principio: qué > cómo/ quién > dónde/ por qué > cuándo > cuál.

Por lo que respecta al tiempo y al modo verbal, en principio, cualquiera es admitido, pero los más empleados son el presente de indicativo, para sugerencia, los pretéritos perfectos y el futuro de conjetura.

\section{DOCUMENTACIÓN HISTÓRICA (MEDIEVAL Y CLÁSICA)}

Sin ánimo de efectuar un estudio histórico detallado de este fenómeno en esta ocasión, aspecto que dejamos para un futuro trabajo, es interesante subrayar dos hechos en 
relación a la diacronía de estas construcciones: i) que presentan una continuidad notable a lo largo de la historia de la lengua española, y ii) que sus primeras documentaciones aparecen en textos dialogados medievales y clásicos, tanto en verso como en prosa $^{13}$. Estas primeras conclusiones las obtenemos tras una revisión detallada de los datos del CORDE y del Corpus del español: Género/Histórico. Según estas dos fuentes, el primer ejemplo histórico registrado data del siglo XIV y es del nombre diablos:

(10) Estonçe dixo Rodrigo. Conde por que vos quexades tanto.

Que a quien diablos han de tomar chica es posiesta de mayo.

Essas horas dixo el rey. ve tu via bien aventurado (Mocedades de don Rodrigo, BNP, Esp. 12, s. XIV).

Otros ejemplos, con los nombres enfáticos diablos (cf. 11a), rábanos (cf. 11b) y demonio (cf. 11c, ejemplo a caballo entre la significación de un nombre común y otro enfático, quizá determinada por su forma en singular) se documentan en diálogos de obras de teatro y novelas del siglo XVI:

(11) a. Sircelo: Pues dezí.

Giliracho: Ellos estaban assí.

Sircelo: ¿Ellos? ¿quién? ¿qué diablos abláis?

Giliracho: La, la, seño... (Jaime de Huete, Comedia Tesorina, 1528).

b. El Sancho fuese al torno, y, tocando, respondiéronle: -Ave María. Dijo el vizcaíno: -No pides Ave María, que rábanos quieres, que mi tío mesa aguardas (Juan de Timoneda, Buen aviso y cuentacuentos, 1564).

c. Y vosotros, traidores de Hazán, ¿qué demonio os ha movido a acometer tan grande insulto? ¿Cómo por cumplir el apetito lascivo del que aquí os envía queréis ir contra vuestro natural señor? (Miguel de Cervantes, El amante liberal, 1582).

El paso del tiempo muestra que durante el siglo XVII estas construcciones amplían su rango de uso y admiten otros sustantivos. En efecto, aparecen nombres enfáticos conocidos previamente como demonios (cf. 12b) y diablos (cf. 12c), pero también otros "nuevos" como cuentos (cf. 12a) y narices (cf. 12d), de nuevo en textos dialogados (comedias, novelas y coloquios):

(12) a. Cervino: Si acaso pasaren algunos a caballo, entraos luego en el patio, hace llamar a mi mujer con algún achaque y entretenedla, desde abajo, con cualque conseja como de brujas

13 Tal y como ha mostrado Unceta Gómez (2016), en el propio latín algunos sustantivos de carácter interjectivo, como malum! ('problema, castigo'), se empleaban para manifestar desacuerdo: «Qui, malum, intellegere quisquam potis est?» (Plauto, Amphitruo, 625-626) (Pero, ¿cómo diablos se puede entender eso?); «Quid tu, malum, in os igitur mi ebrius inructas?» (Plauto, Psendolus, 1295) (Y tú ¿por qué diablos me eructas tu borrachera en la cara?). El uso de los sustantivos enfáticos es, por tanto, herencia latina. 
y hechiceras hasta que veáis que han pasado y que no vuelven, que todo es menester para que no se ponga a la ventana.

Inocencio: ¡Pues qué cuentos sé yo para eso! Tendréla dos horas con un palmo de oído escuchándome. Déjeme vuesa merced con ella (Diego Alfonso Velásquez de Velasco, El celoso, 1602).

b. ¿Adónde va, señor don Quijote? ¿Qué demonios lleva en el pecho, que le incitan a ir contra nuestra fe católica? Advierta, mal haya yo, que aquélla es procesión de diciplinantes, y que aquella señora que llevan sobre la peana es la imagen benditísima de la Virgen sin mancilla (Miguel de Cervantes, Don Quijote de la Mancha, 1605).

c. Berganza: Mucho sabes, Cipión. ¿Quién diablos te enseñó a ti nombres griegos?

Cipión: Verdaderamente, Berganza, que eres simple, pues desto haces caso; porque éstas son cosas que las saben los niños de la escuela (Miguel de Cervantes, El coloquio de los perros, 1613).

d. Aldonza: ¡Ay triste de mí! Leonor, mi mal crece de hora en hora.

Leonor: ¿Qué sientes?

Aldonza: Don Juan agora me ha parecido peor. ¿Qué narices! (Juan Ruiz de Alarcón, Quien mal anda en mal acaba, c. 1628).

Como hemos mencionado previamente, el estudio de la modificación nominal enfática desde un punto de vista diacrónico amerita un estudio independiente. Me limito en esta ocasión a dejar constancia de su empleo antiguo. Sin embargo, muy probablemente la descripción de los valores de estas construcciones que presento a continuación pueda tener valor general y se pueda aplicar tanto a la situación histórica como a la actual.

\section{LOS VALORES DE ESTAS UNIIDADES}

Tras conocer la estructura básica de estas construcciones (nombres enfáticos e interrogativos), la distribución geográfica de algunos de ellos y su documentación histórica, es necesario volver sobre los valores semánticos y pragmáticos que presentan, en relación a su combinatoria sintáctica. En términos generales, podemos convenir que implican una actitud de impaciencia o molestia por parte del hablante (Huang y Ochi, 2004). Por ello, los valores que transmiten son los de fastidio, incomodidad, enojo, impaciencia o desesperación ante una situación adversa (cf. 13ab). Pueden servir, además, para negar la existencia de una persona, lugar o cosa en respuestas o réplicas negativas (cf. 13c). Lo más habitual es que se empleen cuando el hablante no encuentra el significado a algo, o cuando carece de información al respecto, porque debería ser accesible o porque no es fácil obtenerla (cf. 13d). 
(13) a. Con quien sí tengo una bronca de la pesada, sería con los enlatados de Canal 9, SNT, Cerro corá o como carajo se llame... Si bien importan algunos productos buenos, dejan grandes baches en la industria televisiva que con tanto esfuerzo queremos consolidar (Paraguay).

b. el hijo de Pasman, de unos 20 años, prepara el bolso para ir a jugar un partido de fútbol. ¿Dónde carajo están las plantillas de los botines?, dice. Golpea las puertas de los muebles. Larga el aire con fuerza y pesadez, como si tuviera ganas de que los periodistas percibieran su enojo (Argentina).

c. Y vas a levantarte un día y todo eso habrá terminado. Las entregas, las planificaciones, las organizaciones de obras. Y tendrás el papel ese en la mano con el maravilloso título de arquitecto, pero ¿quién carajos va a querer celebrar con vos? Nadie (Honduras).

d. ¡Me tienes mal, coño! ¡Me gusta todo lo que veo de ti! ¿Qué carajo quieres que haga? Me di cuenta que me había enamorado de ti... (Venezuela).

Como vimos supra, el nombre enfático solo es compatible cuando el hablante desconoce la respuesta adecuada a la pregunta, y se vincula a un referente ya presente (Gutiérrez-Rexach, 2002, pp. 115-116), de ahí que oraciones como (14c) no sean posibles en español:

(14) a. Sé lo que Carmen le dio a Juan.

b. No sé qué demonios Carmen le dio a Juan.

c. *Sé lo que demonios Carmen le dio a Juan.

En este caso concreto (cf. 14b) el nombre enfático demonios extiende el dominio de cuantificación para incluir valores 'familiares' y 'novedosos', lo que se conoce como extensión de dominio (domain extension, den Dikken y Giannakidou, 2002, p. 43) ${ }^{14}$. Por ello, estas oraciones suelen ser extrañas con verbos no compatibles con la actitud, como saber, que denota proposiciones no preguntas (cf. 14c). De hecho, se emplean para expresar emociones fuertes, como la sorpresa o la frustración (cf. 14b). Retomando las ideas de Oguro (2017), estas estructuras serían una reminiscencia de los predicados de afección o factivos que expresan reacciones afectivas o emocionales, como lamentar(se), sorprender(se) o molestar(se), verbos que presuponen la verdad de su complemento (RAE/ASALE, 2009, p. 1882).

Por otro lado, como ya propuso Cinque (1999), en la gramática existe una Frase de actitud, por lo que el valor pragmático resulta especial en estas construcciones. En otras

14 Especialmente en contextos con interpretación anafórica de demonios a un referente introducido previamente: Alguien compró este libro. Juan sabe quién / * quién demonios, donde quién se vincula al discurso previo, pero quién demonios no se puede vincular. 
palabras, la existencia de esta proyección indica que son oraciones (preguntas y exclamaciones) con una actitud ${ }^{15}$. Por ello, se emplean cuando el hablante tiene una actitud particular: de impaciencia, molestia, fastidio, incomodidad, enojo, ira, desesperación, frustración, sorpresa, etc.

De este modo, son compatibles con preguntas insertadas o incrustadas (Huang y Ochi, 2004), donde la actitud puede atribuirse al hablante (cf. 15a):

(15) a. Es un completo misterio (saber) por qué demonios se marchó.

b. *Es completamente obvio por qué demonios se marchó.

c. Es completamente obvio por qué se marchó.

Pero también esa actitud puede atribuirse al sujeto, como hablante interno (cf. 16a):

(16) a. Juan se pregunta por qué demonios Luis dijo eso.

b. ?Juan sabe por qué demonios Luis dijo eso.

c. Juan sabe por qué Luis dijo eso.

Los ejemplos donde la pregunta incluye un nombre enfático como demonios (cf. 15a y 16a) sirven para expresar las emociones del hablante, básicamente ira o frustración, y el nombre demonios solo es compatible con la situación en la que el hablante no tiene idea de cuál puede ser la respuesta adecuada a la pregunta. Como vimos, estas construcciones se emplean para negar la existencia de una persona, lugar o cosa (iQuién demonios se cree que es?), y cuando el hablante no encuentra el significado a algo, o carece de información al respecto (¿Dónde coño has puesto las llaves del auto?).

\section{CONCLUSIONES}

La realización de este trabajo nos ha permitido describir y conocer un poco mejor un tipo de estructuras que presuponen la existencia de una respuesta, pero que la falta de disponibilidad o conocimiento de dicha respuesta provoca el uso de un nombre enfático. Además, la emoción o actitud negativa que viene con la inclusión del nombre enfático es señal de que el hablante no conoce la respuesta, por lo que claramente modulan su intención oracional.

\footnotetext{
15 Para autores como Huang y Ochi (2004, p. 285), por ejemplo, la especificación de la Frase de actitud (Attitude Phrase) contiene un rasgo [+ wh] vacío esperando ser verificado. Los nombres del tipo demonios se fusionan como especificadores (Spec) de la Attitude Phrase. Campos (2012, p. 402) los denomina "interrogatives with an attitude".
} 
Resumo, a continuación, sus propiedades más importantes: i) la presuposición existencial o valor pragmático que presentan; ii) la "ignorancia" del hablante con respecto a la respuesta; y iii) la actitud que muestran (frustración, ira, etc.). Por todo ello, la combinación de una palabra-Q y un nombre enfático solo es posible cuando el hablante no conoce la respuesta a la pregunta.

Por otro lado, el interrogativo que más se emplea, según los datos revisados, es qué (y el que menos es cuál). La lista de nombres enfáticos presentada, una de las pocas con que contamos, no resulta completa porque, en principio, cualquier nombre puede adquirir un nuevo valor pragmático-contextual y convertirse así en nombre enfático.

Hemos visto también que, en general, la distribución de estas construcciones es amplia (carajos, demonios), aunque algunos de los nombres enfáticos o intensivos están muy localizados geográficamente (narices, puñetas). Por último, hemos comprobado que su uso se documenta en español antiguo.

Con todo, la descripción del fenómeno en estudio no se agota aquí, ya que quedan pendientes varios asuntos de gran interés, en relación sobre todo a su comportamiento sintáctico y su comparación con otras lenguas, así como su inclusión y tratamiento en los diccionarios, además de su documentación histórica. Aspectos que podrán ser tratados en futuros trabajos.

\section{BIBLIOGRAFIA}

Asociación de Academias de la Lengua Española (2010). Diccionario de americanismos. Lima: Santillana.

Ballesta García, M. D. (2001). Algunos recursos de caracterización tipológica en Alcifrón, Anuario de Estudos Filológicos, XXIV, pp. 39-53. https://doi.org/10.1002/9781118358733.wbsyncom106

Bayer, J. y L. Lai-Shen Cheng (2017). Wh-in-situ. En M. Everaert y H. C. van Riemsdijk (eds.), The Wiley Blackwell Companion to Syntax, 2nd Edition. Oxford: Wiley-Blackwell, vol. VII, pp. 4250-4277.

Campos, H. (2012). The Simple Sentence. En J. I. Hualde, A. Olarrea y E. O’Rourke (eds.), The Handbook of Hispanic Linguistics. Oxford: Wiley-Blackwell, pp. 395-421. https://doi.org/10.1002/9781118228098.ch20

Casares, J. (1969). Introducción a la lexicografía moderna. Madrid: CSIC, Anejos de la Revista de Filología Española.

Cinque, G. (1999). Adverbs and functional heads. Oxford y Nueva York: Oxford University Press.

Company Company, C. (2017). Plurales que no son plurales. Una aportación del español a la tipología del reanálisis, Lingüística, 33(1), pp. 73-87. https://doi.org/10.5935/2079-312X.20170005 
CORDE $=$ Banco de datos, Corpus diacrónico del español. Madrid: RAE. [en línea] www.rae.es [27/04/2020]. Covarrubias, S. de (1611). Tesoro de la lengua castellana o española. Madrid: Luis Sánchez impresor.

Davies, M. Corpus del español. Provo: Brigham Young University. [en línea] www.corpusdelespanol.org [27/04/2020].

Den Dikken, M. y A. Giannakidou (2002). From Hell to Polarity: «Aggressively Non-D-Linked» WhPhrases as Polarity Items, Linguistic Inquiry, 33(1), pp. 31-61. https://doi.org/10.1162/002438902317382170

Di Tullio, Á. (2010). Preguntas hendidas y preguntas segmentadas, Cuadernos de la ALFAL, 1, pp. 70-82.

Domínguez, R. J. (1846-1847). Diccionario Nacional o gran diccionario clásico de la lengua española. Madrid: Mellado.

Echegaray, E. de (1887-1889). Diccionario general etimológico de la lengua española. Madrid: Álvarez hermanos impresores.

Fiengo, R. (2007). Asking Questions. Using Meaningful Structures to Imply Ignorance. Oxford: Oxford University Press. https://doi.org/10.1093/acprof:oso/9780199208418.001.0001

Gutiérrez-Rexach, J. (2002). The Semantics of Spanish Free Relatives. En T. Satterfield, Ch. Tortora y D. Cresti (eds.), Current Issues in Romance Languages. Amsterdam y Philadelphia: John Benjamins, pp. 111-128. https://doi.org/10.1075/cilt.220.09gut

Huang, C.-T. J. y M. Ochi (2004). Syntax of the Hell: Two Types of Dependencies. En K. Moulton y M. Wolf (eds.), Proceedings of the thirty-fourth annual meeting of the North East Linguistic Society. Amherst (Mass.): Graduate Linguistics Student Association, pp. 279-294.

Lee, F. (1994). Negative polarity licensing in wh-questions: The case for two licensers. Los Angeles: University of California, Los Angeles.

López Bobo, M. J. (2002). La interjección: aspectos gramaticales. Madrid: Arco/Libros.

Obenauer, H-G. (1994). Aspects de la syntaxe A-barre. Effets d'intervention et mouvements des quantifieurs. París: Université de Paris VIII.

Oguro, T. (2017). The True Nature of WH-the Hell Phrases, Florida Linguistics Papers, 4(2), pp. 113-126. Pesetsky, D. (1987). Wh-in-situ: Movement and Unselective Binding. En E. J. Reuland y A. G. B. ter Meulen (eds.), The Representation of (In)definiteness. Cambridge (Mass.): MIT Press, pp. 98-129.

Quilis Merín, M. (2007). Pragmática y lexicografía histórica del español en el siglo XIX: Ramón Joaquín Domínguez, Quaderns de Filologia. Estudis Lingüistics, XII, pp. 271-287.

Real Academia Española y Asociación de Academias de la Lengua Española (2009). Nueva gramática de la lengua española. Madrid: RAE, Espasa.

Real Academia Española y Asociación de Academias de la Lengua Española (2017-2020). Diccionario de la lengua española. Edición del tricentenario. Madrid: RAE. [en línea] www.rae.es [27/04/2020].

Rivas González, M. (2005-2006). De la interjección al esbozo de una nueva teoría del signo, Contextos, XXIII-XXIV (45-48), pp. 303-321. 
Unceta Gómez, L. (2016). Cuando los sentimientos irrumpen: análisis de las interjecciones secundarias en las comedias de Plauto. En B. García Hernández y M. A. Penas Ibáñez (eds.), Semántica latina y románica. Unidades de significado conceptual y procedimental. Berna y Nueva York: Peter Lang, pp. 213-

241. 